\title{
EM BUSCA DE UMA COMPREENSÃO DOS SIGNOS NA PROPAGANDA DO GOVERNO MILITAR
}

Trying to understand the sings of propaganda in Brazilian military Government

Flailda Brito Garboggini ${ }^{1}$

\begin{abstract}
Resumo
O objetivo deste trabalho foi conhecer um pouco da história, através de alguns elementos presentes na memória pessoal e na mídia, dos anos do governo militar. Notadamente, procuramos observar, através da mídia, algumas das tendências da censura e da interferência do Governo na sociedade. Realizamos estudos sobre os fatos políticos que marcaram a época e realizamos um levantamento de anúncios veiculados na mídia da época relacionados, de algum modo, com os fatos regidos pela "linha dura" e ufanista do governo do período.
\end{abstract}

Palavras-chave: história, mídia; memória; propaganda.

\begin{abstract}
The aim of this work was to learned about history and influences of the military government in brazilian media and advertisements. More precisely, we are looking at the tendencies of censorship and the interferencies of the government on the media and on society in general, during the period of time the military remained in power. We are developing a study about the political aspects that marked these years and we analyze the media and some TV's advertisement that tried to hide the real facts, that were sustaining the "UFANISTA"'s government since then.
\end{abstract}

Keywords: advertisement, history, media, memories.

\section{Resumen}

El objetivo de este trabajo és conocer un poco de historia a través de algunos elementos presentes en la memória personal y de los medios de comunicación, en los años de Régimen Militar. En particular, se observa a través de los medios de comunicación,algunas de las tendencias de la censura y la interferencia del gobierno en la

\footnotetext{
${ }^{1}$ Professora da Faculdade de Publicidade e Propaganda da PUC-Campinas, doutora em Ciências da Comunicação ECAUSP. Contato: flaildabg@hotmail.com.
} 
Em busca de uma compreensão dos signos na propaganda no governo militar de Flailda Brito Garboggini

sociedad. Llevamos a cabo los estudios sobre los acontecimientos políticos que marcaron la temporada y hemos hecho un estudio de los anuncios en los medios de comunicación de la época conectado de alguna manera con los hechos objeto de la "línea dura" del gobierno del período.

Palabras-clave: publicidad, historia, medios de comunicación, recuerdos.

\title{
1. INTRODUÇÃO
}

\author{
"Caminhando e cantando e seguindo a canção, \\ aprendendo e ensinando uma nova lição. \\ Vem, vamos embora que esperar não é saber, \\ quem sabe faz a hora, não espera acontecer..."
}

Esta belíssima música de Geraldo Pedroso de Araújo Dias Vandregísilo, ou simplesmente Vandré, fazia arrepiar, era emocionante, mas nem todos, como eu, compreenderam o que estava por trás. Os festivais da TV Record, em São Paulo, tinham audiência altíssima quando venceram as músicas: "Disparada", de Vandré, "A banda" (1967) e "Roda viva" (1968), de Chico Buarque. No Rio havia o Festival Internacional. Muitos compositores iniciaram suas carreiras nesses eventos de grande audiência na época. Uns continuaram bem e alcançaram grande sucesso, como Caetano, Gil, Milton Nascimento e Chico. Entretanto, Geraldo Vandré finalizou muito cedo sua carreira, talvez por ter sido ousado demais, com músicas de protesto.

Não só no meio artístico, mas no Brasil, muita gente desapareceu neste período. Eu não conhecia nenhum estudante que tivesse participado de movimentos. Estudava em colégio religioso, onde só entravam meninas, e tudo era muito protegido e controlado, inclusive o que os professores podiam falar. Não entendia o que estava acontecendo. Em 1964, aos 12 anos, percebi que algo atípico estava ocorrendo, mas não dei muita importância. Com o tempo, fui percebendo outras coisas estranhas, devíamos ter cuidado com o que falávamos entre amigos e colegas e, mesmo em casa, muitas palavras não deviam ser ditas, comunismo era uma delas. Muitas conversas entre os adultos eram veladas, em voz baixa ou longe dos mais jovens.

Um dia, em 1968, presenciei uma passeata de estudantes universitários no centro de Campinas, onde sempre morei. Não imaginava que tantas desgraças estavam REVISTA SIGNOS DO CONSUMO - V.2, N.1, 2010. P. 82-97. 
Em busca de uma compreensão dos signos na propaganda no governo militar de Flailda Brito Garboggini

acontecendo em tantos lares nos anos que se seguiram àquele fatídico "dia do golpe militar".

No meu colégio, todo dia 31 de março, a partir de 1965 (ao menos até 1970, último ano em que estive lá), era marcado por uma comemoração. Discursos, enfatizando os grandes feitos e vantagens da revolução, como a recuperação e a manutenção da ordem no país, eram proferidos por militares.

Em vários locais, alertas contra o regime comunista eram apresentados de diferentes formas. Falava-se que idosos eram mortos, por não serem mais produtivos. Histórias de pessoas impedidas de sair de seus países, como da antiga Tchecoslováquia eram temas amplamente destacados nas revistas Manchete e Cruzeiro, o que me impressionava profundamente. Enfatizava-se a perda total da liberdade de ir e vir dos habitantes, enquanto aqui se destacava, enfaticamente, nossa liberdade. Com efeito, apontavam nossos privilégios e como estávamos sendo protegidos da entrada do comunismo pelo governo. Os discursos ufanistas e o "milagre econômico brasileiro" dos políticos-militares e dos civis aderentes eram uma constante nos meios de comunicação de massa de grande audiência.

Anos mais tarde, procurei entender melhor o estilo e a abordagem dos discursos da mídia, neste que foi, segundo Dines (2004), “o pior período do governo militar, em que a sociedade se viu tolhida de liberdade, em que as opiniões contrárias ao novo regime foram totalmente tolhidas, chegando-se a extremos absurdos, como desaparecimento de pessoas por terem expressado opiniões consideradas inadequadas". Entre outros aspectos, me interessava descobrir a forma como alguns veículos e, em especial, as empresas anunciantes se envolveram com a situação política da época.

Pode-se notar que a propaganda do regime militar mostrava claramente a visão que os próprios militares tinham de seu governo e de seu país, divergindo das perspectivas de jornalistas conceituados, impedidos de mostrar a realidade. O que se pode concluir é que isso resultou em uma descrença generalizada na democracia. Dines confirma que, até hoje, ficou evidenciada uma crise de valores que gerou ignorância sobre os fatos e, pior, uma apatia política em muitos cidadãos.

De acordo com Maria Lygia Quartim de Moraes (in Reis, Ridenti e Motta, 2004, p. 300), o golpe militar de 1964 foi uma grande tragédia política, com consequências nas vidas pessoais daquela geração. Ameaçavam e puniam pessoas mesmo sem certeza ou provas de que eram realmente terroristas como supunham. Para se ter uma ideia, no filme Zuzu Angel (2006), Sérgio Rezende retrata fatos do período, em que os REVISTA SIGNOS DO CONSUMO - V.2, N.1, 2010. P. 82-97. 
Em busca de uma compreensão dos signos na propaganda no governo militar de Flailda Brito Garboggini

representantes do governo negavam prisões, torturas ou o desaparecimento de pessoas.

Demorou muito tempo para que a população, de modo geral, fosse informada, sobre essa realidade encoberta: as dolorosas perdas de pessoas e, principalmente, os horrores realizados pelo sistema. E foi justamente a própria mídia, através de casos especiais de TV, do cinema, de entrevistas e de depoimentos, após 20 anos do final da ditadura, que passou a contar os fatos que muitos, até hoje, pensam ser ficção.

Vários filmes foram realizados na tentativa de denunciar os acontecimentos. Porém, Arnaldo Jabor arriscou-se lançando, em 1970, Pindorama. Posteriormente, ficou menos problemático tratar do assunto. Para não deixar esquecer a gravidade dos fatos o tema apareceu em Pra frente, Brasil (1982), o primeiro longa-metragem que tratou abertamente da tortura na ditadura militar. Nessa esteira, outros foram surgindo, como: Lamarca (1994), O que é i sso, companheiro (1997), Vlado - Trinta anos depois (2005), O ano em que meus pais saíram de férias (2006), Batismo de sangue (2007) e Travessia (2008). Seus diretores concordam que o cinema ajuda a preservar a memória, mas, principalmente, ajuda a esclarecer certos aspectos dela, mostrando outro lado de fatos que ficaram escondidos.

Demorou justamente 20 anos para se poder falar mais claramente sobre o assunto e Zuenir Ventura (1988) lançou a obra: 1968: o ano que não terminou, em que reconstituiu, sobretudo, o ano mais fervilhante do período. Seu trabalho foi possível graças à investigação nos jornais e revistas da época e a entrevistas com personagens sobreviventes, procurando falar de "uma geração que queria virar o mundo do avesso". Foi através dessa obra que pude começar a abrir uma cortina fechada em minha mente por tantos anos.

\section{ANTECEDENTES E CIRCUNSTÂNCIAS}

A década de 60 foi revolucionária. Foram os anos da minissaia, dos homens de cabelo comprido, da pílula anticoncepcional, da guerra do Vietnã, dos hippies, do feminismo, da Revolução Cultural na China, da Primavera de Praga, dos Beatles, dos Rolling Stones, de Jimi Hendrix e Janis Joplin, do psicodelismo, do amor livre. O homem pisou na lua. A guerra fria de Kennedy e Krutchev e a revolução da China de Mao Tse Tung foram assuntos destacados na mídia. No cinema, assistimos a filmes de Godard, Pasolini e Antonioni. Na literatura destacaram-se mundialmente as ideias e os livros de Sartre, Marcuse, Althusser, Hermann Hesse, Erich Fromm e Wilhelm Reich. A REVISTA SIGNOS DO CONSUMO - V.2, N.1, 2010. P. 82-97. 
Em busca de uma compreensão dos signos na propaganda no governo militar de Flailda Brito Garboggini

medicina avançou com transplantes de coração, enquanto o computador começou a aparecer entre nós.

O aparecimento, na década de 60, de uma juventude extremamente politizada e militante em todo o mundo ocidental parece ter sido o estopim do alerta das forças de direita. Os jovens e intelectuais formaram, entre os anos 60 e 70, a organização denominada de "nova esquerda", bem representada pelos estudantes universitários. Eram, então, uma força política importante e acabaram sendo as principais vítimas da repressão político-militar. Por isso, segundo Maria Lygia Quartim de Moraes (ibidem, p. 298), "ditaduras do mundo todo adotaram como uma de suas medidas iniciais invadir universidades, colocar na clandestinidade as centrais estudantis e prender professores e alunos". De 1965 a 1968, a resistência política deslocou-se, principalmente, para a esfera intelectual e artística. Efetivamente, "no Brasil, as correntes políticas de direita e de esquerda desenvolveram-se no interior da universidade pública, importante formadora da elite intelectual e profissional, que constituiu um monopólio quase completo do ensino universitário até os anos 70" (idem, p. 299). Posteriormente, com a repressão, os estudantes foram calados e, pouco a pouco, se afastaram da participação do movimento político, a ponto de, hoje, percebermos que a maioria de nossos alunos não tem a mínima ideia do que foi aquele período e da forma pesada de tortura imposta aos rebeldes.

De acordo com Azevedo (2004, p. 4), “poucas vezes um presidente da República assumiu o poder em circunstâncias tão difíceis quanto João Goulart”. Existiam, então, forças antagônicas prestes a um confronto armado. De um lado, o projeto de desenvolvimento capitalista nacional, reformista que objetivava independência em relação aos EUA e à Europa e, de outro lado, o projeto de liberação do câmbio, defensor de controle da inflação e da abertura do país ao capital estrangeiro. Era o auge da guerra fria entre EUA e URSS, após a vitória da revolução de Cuba. Nesse contexto, Jango assumiu o governo em 7 de setembro declaradamente com tendências de esquerda.

Os meses do início do governo de Jango foram marcados pelo receio de novas tentativas de golpe militar. Houve, então, como medida de segurança, o estabelecimento do parlamentarismo, em que o presidente não exerce o poder executivo, mas sim o primeiro ministro. Porém, foram propostas e realizadas eleições para decidir se o povo optaria pela continuidade desse sistema e, nas eleições, o presidencialismo foi vitorioso, voltando o poder executivo às mãos de Jango.

A atuação das massas urbana e rural em favor das "reformas de base" - agrária, REVISTA SIGNOS DO CONSUMO - V.2, N.1, 2010. P. 82-97. 
Em busca de uma compreensão dos signos na propaganda no governo militar de Flailda Brito Garboggini

política e bancária -, apoiadas pelo presidente João Goulart, provocou o confronto com os grupos sociais tradicionais.

Utilizando o argumento anticomunista e anticorrupção, um movimento militar depôs o Presidente João Goulart em 31 de março de 1964. Nove dias após, o Comando Supremo da Revolução - formado pelos comandantes-em-chefe do Exército, da Marinha e da Aeronáutica - editou o Ato Institucional $n^{\circ} 1$, determinando ficarem suspensos, por dez anos, os direitos políticos de diversos cidadãos vistos como opositores ao regime, dentre eles congressistas, militares e governadores. Surgia aí a ameaça de cassações, prisão, enquadramento como subversivos e eventual expulsão do país.

A eleição indireta do presidente da República foi institucionalizada. Desta forma, apenas o colégio eleitoral, composto pelos congressistas, que supostamente representavam os anseios e desejos da população, poderia eleger o Presidente da República. O golpe efetuado pelos militares em 1964 atingiu totalmente a democracia brasileira.

A participação dos militares no governo já acontecia desde o Império, mas, em 1964, a intervenção foi mais forte, gerando medo na população porque incorporou ameaça, perseguição, tortura e morte ao dia-a-dia dos brasileiros que não seguiam os padrões esperados pelo governo.

O primeiro presidente militar, General Humberto de Alencar Castello Branco, foi eleito pelo Congresso em sessão pública e votação nominal, em 11 de abril de 1964 , estendendo-se seu mandato até março de 1967.

Seu sucessor, General Arthur da Costa e Silva, teve uma gestão marcada pela intensificação da repressão política, ainda mais fortalecida com a decretação do AI5 (Ato Institucional no 5), no final de 1968. Em 1969, criou em São Paulo a Operação Bandeirantes (Oban), embrião dos Destacamentos de Operações de Informações - Centro de Operações de Defesa Interna (DOI-CODIs estaduais). Diversos outros atos institucionais e complementares foram estabelecidos na sequência, implantando, definitivamente, uma Ditadura Militar muito dura no país. O presidente tinha poder total, podia fechar os poderes legislativos federais, estaduais e municipais, tudo em nome da segurança nacional. Prisões arbitrárias, cassações políticas, intervenções em sindicatos e universidades e tortura foram métodos amplamente utilizados, sobretudo para aqueles que contradiziam as regras do sistema em implantação no país. O medo de que o comunismo fosse implantado, aparentemente, era o maior motivo de tanta arbitrariedade. 
Em busca de uma compreensão dos signos na propaganda no governo militar de Flailda Brito Garboggini

Zuenir Ventura (1998, p. 126) classifica os presidentes do período: “o Seu Arthur (Costa e Silva) foi realmente o mais simpático dos cinco ditadores que governaram o país de 64 até a abertura, e infinitamente melhor do que os três colegas que o sucederam na Junta. (...) estava longe do pedantismo de Castello Branco, do obscurantismo de Médici, da auto-suficiência de Geisel ou da grossura assumida de Figueiredo".

Em agosto de 1969, por problemas de saúde, Costa e Silva foi afastado e substituído pelo General Emílio Garrastazu Médici. Nesse governo, finalizado em março de 1974, efetivamente, o recrudescimento do regime se intensificou mais com a criação definitiva dos DOI-CODIs estaduais, em maio de 1970, financiados por empresários. Esses órgãos eram os responsáveis pela repressão imposta à população brasileira.

Pode-se afirmar que Médici conduziu o governo com punho de aço, naqueles que foram chamados de "anos de chumbo", de repressão brutal.

De 1974 a 1979, o General Ernesto Geisel deu início a uma certa abertura, que veio "lenta e gradualmente". Foi no governo do General João Batista Figueiredo, no poder até março de 1985, que ocorreu um certo afrouxamento do rigor do sistema de governo.

Infelizmente, na sequência, mesmo tendo sido eleito um presidente com tendências democráticas, quem realmente governou foi o Vice-Presidente Sarney, pois Tancredo Neves veio a falecer antes de assumir o novo governo. Mistérios circundam os reais motivos de sua morte e isso daria margem para uma nova pesquisa, que deixamos para outra oportunidade.

\section{A PROPAGANDA COMERCIAL E POLÍTICA}

A propaganda, como um dos elementos concorrentes para realizar os objetivos de instituições, de acordo com sua filosofia, procura alterar atitudes, ou predisposição dos indivíduos em relação a algo ou alguém. Enquanto expressões detectáveis das atitudes, as opiniões da população são intensamente estudadas antes da realização das campanhas, tendo em vista encontrar as melhores e mais oportunas soluções para promover um bem ou uma instituição. Adaptando-se à situação, este princípio é válido também na propaganda política a ser estabelecida em um país. Na situação do novo sistema ditatorial, lançou-se mão do poder, com uma forma agressiva e impositiva. $\mathrm{O}$ autoritarismo predominou através da coerção e da força em relação aos antagônicos. 
Em busca de uma compreensão dos signos na propaganda no governo militar de Flailda Brito Garboggini

Os fatos sociais e políticos estão totalmente vinculados ao conceito de atitude do indivíduo e, em nossa tese, foram reforçados tanto pela propaganda política como pela publicidade comercial da época. Percebe-se que houve grande interesse das empresas coniventes, e portanto protegidas pelo governo, de forma a conduzir, em conjunto, a população brasileira na direção desejada pelos dominantes.

Através da análise da mídia e, especificamente, do material publicitário veiculado, pode-se identificar tipos de referência e valores marcantes da história da nossa sociedade.

Os símbolos nos materiais de divulgação, como cartazes, pôsteres e diversos outros anúncios impressos, assim como jingles e imagens, podem falar de forma indireta, atuando no inconsciente das pessoas. Os símbolos nacionais e as forças que os governos exerceram deixaram transparecer o que foi realmente apresentado e aceito pela maioria da população.

No Brasil da ditadura houve uma efetiva aquiescência da grande massa urbana. O governo parece ter sido capaz de calar ou emudecer muitos dos líderes "revolucionários", a ponto de grande parte da população, senão a maioria, convencer-se de que finalmente o país iria para frente após o período de grande inflação dos governos anteriores. Com a renúncia de Jânio Quadros, em agosto de 1961, o Brasil vivia uma crise econômica grave.

Com efeito, os movimentos contrários ficaram bastante concentrados nos redutos estudantis e artísticos, que foram duramente controlados. A grande maioria da população se sentia segura e esperançosa de que o governo estava fazendo tudo pelo bem do Brasil. A propaganda governamental e o controle pela censura foram bastante eficientes para neutralizar e evitar que a população soubesse exatamente o que acontecia, calando e eliminando os movimentos contrários.

O status quo da ditadura militar possuía alguns jargões próprios para se promover, entre eles: "Brasil grande”, “integração nacional”, "ame-o ou deixe-o", "ilha de paz", "pra frente Brasil", "ninguém segura este país", entre outros. Todos eles embasavam a ideia que se concretizou, na sequência, no chamado "Milagre Brasileiro", com a noção de um futuro melhor e promissor.

Pyr Marcondes (2001), mostra que o endurecimento político foi mascarado pelo "milagre econômico", crescimento extraordinário do PIB (cerca de 10\% ao ano), diversificação das atividades produtivas e o surgimento de uma nova classe média com alto poder aquisitivo. Tudo isso repousando sobre o aumento estrondoso da concentração REVISTA SIGNOS DO CONSUMO - V.2, N.1, 2010. P. 82-97. 
Em busca de uma compreensão dos signos na propaganda no governo militar de Flailda Brito Garboggini

de renda, dando-nos o título de país mais injusto do planeta. O dito crescimento econômico deveu-se ao Plano Nacional de Desenvolvimento, cujo artífice era o então ministro Delfim Neto. Porém, iniciou-se um processo galopante de endividamento, que não se reverteu em uma distribuição mais equitativa da renda, mas que serviu para custear obras faraônicas, tais como a Ponte Rio-Niterói, a Transamazônica, a Usina de Itaipu etc.

A televisão brasileira transformou-se a partir deste período no grande veículo de comunicação e da cultura de massa, permitindo aos brasileiros receber entretenimento de boa qualidade enquanto o jornalismo e o acesso à informação eram controlados totalmente pela censura.

O crescimento da liderança da TV sobre os demais veículos deveu-se, sobretudo, à sua vocação para a integração nacional. Com o desenvolvimento da estrutura de telecomunicações montada no país pela Embratel, foi concretizada a integração nacional, campo fértil para o desenvolvimento da propaganda brasileira.

Com a técnica já evoluída da publicidade, a televisão serviu como uma luva para o movimento militar. O ufanismo nacionalista, a ideologia progressiva, a busca pela criação de um sentimento pátrio profundo foram temas e conceitos aos quais a propaganda aderiu.

O governo, com toda a sua estrutura centralizada de poder - e suas ramificações, com estatais, autarquias, ministérios, secretarias -, transformou-se no maior anunciante do país, favorecendo que muitas empresas do setor de comunicação progredissem e que a propaganda, como negócio, crescesse como nunca.

As agências de propaganda alcançaram, então, uma força que perderiam substancialmente nos anos 80. Essas empresas de publicidade reuniram-se com representantes do governo, que decidiam as regras do jogo e conseguiram aprovar, em 1965, a Lei 4.680 - marco importante da história da propaganda brasileira. Esta foi bastante vantajosa para o setor, porque definia que a remuneração-base das agências saltaria dos 17,65\%, pagos até então sobre as verbas investidas pelos anunciantes na mídia, para 20\%. Esse pequeno percentual e a força da Lei 4.680/1965 construíram as bases para a expansão e a consolidação da propaganda como um setor de negócios de verdade no país.

\section{RELAÇÃO GOVERNO E PROPAGANDA}


Em busca de uma compreensão dos signos na propaganda no governo militar de Flailda Brito Garboggini

Nos primeiros anos da década de 70, o governo, com sua propaganda, conseguiu gerar a euforia do nacionalismo exacerbado sob o slogan "Pra frente Brasil". Outros conceitos importantes também foram introduzidos, como "Ontem, hoje, sempre Brasil", além de "Brasil ame-o ou deixe-o", contra-referência aos movimentos de resistência ao "Golpede 64", dos chamados "terroristas", que lutavam na clandestinidade contra os militares.

Como era proibido dizer coisas diretamente, em função da censura, falava-se por códigos e metáforas. O "milagre brasileiro", como se convencionou chamar essa fase inicial dos anos 70, ia a todo vapor, expresso em índices espantosos de crescimento do PIB, da indústria e do comércio. Foi a época das obras grandiosas, como o projeto Jarí, a hidrelétrica de Itaipu, a ponte Rio-Niterói e a Transamazônica.

A relação entre agências de propaganda e os militares foi muito boa e íntima nessa época, pois era preciso cultivar a ideologia da expansão numa forte mensagem de otimismo e valorização de feitos e conquistas nacionais. A economia do Estado passou a concorrer diretamente com a economia privada e a controlar, de fato, a maior parte da economia.

Assim, era preciso anunciar. O governo investiu substancialmente em publicidade e relações públicas para consolidar sua obra e difundir seus valores. Transformou-se desde então no maior anunciante do país. Coube aos publicitários darem imagem e voz a esse discurso oficial. Foram produzidas campanhas aparentemente inocentes, porém, carregadas de ideologia, comunicando os princípios da doutrina militar dominante.

O marketing ganhou grande impulso no Brasil. Com técnicas importadas dos Estados Unidos, como exemplo de sucesso na explosão do consumo após a segunda guerra, ajudou no desenvolvimento de novos modelos de abordagem do mercado competentes e eficazes.

Muitas marcas e produtos, desta época, tornaram-se inesquecíveis através de jingles e vinhetas muito bem elaboradas, crescendo o raio de expansão com o advento intenso da veiculação em televisão à maioria dos lares brasileiros.

A liberdade era algo problemático, estava sendo usurpada da sociedade, por isso esse tema aparecia em anúncios, gerando no inconsciente coletivo algo que aumentava a atração por produtos que a prometiam em suas mensagens.

A cultura hippie que se apresentava no mundo, com os movimentos de 1968, na França, na Inglaterra, nos Estados Unidos, proliferando por todo o mundo ocidental, não era contestada pelo governo, pois não ameaçava os planos políticos dos governos. Talvez REVISTA SIGNOS DO CONSUMO - V.2, N.1, 2010. P. 82-97. 
Em busca de uma compreensão dos signos na propaganda no governo militar de Flailda Brito Garboggini

por isso, não tenham sido evitados os avanços dessa cultura do "paz e amor" ou "flower power", com os movimentos musicais do rock, nas artes, sobretudo, na música jovem que arrastava multidões para os shows e encontros em praças e espaços públicos. O movimento hippie não foi censurado no Brasil, não tinha um caráter político declarado e, assim, o governo brasileiro não via suas manifestações como ameaçadoras ao sistema.

A excepcional vitória do time brasileiro na Copa do Mundo de futebol em 1970 ajudou a aumentar a popularidade do presidente Médici, que compareceu ao estádio da Cidade do México para comemorar com os jogadores. Foi a primeira copa do mundo transmitida por TV, o que incrementou sobremaneira as vendas de aparelhos televisores. Assim, o feito evidenciou as maravilhas expostas pelo governo, como a construção da transamazônica, a maior obra nacional de integração brasileira, exaltando e enaltecendo os valores brasileiros e todas as grandes obras anunciadas pela mídia. Coincidência ou não, nesse período, as Organizações Globo de Comunicação, com sua TV inaugurada em 1965, por Roberto Marinho, obtiveram um crescimento fenomenal em audiência, chegando a ter a posição privilegiada em audiência, que mantém até hoje.

Do outro lado estão as redes de comunicação que não aderiram ao governo, como a Excelsior, radicalmente impedida em 1969 de continuar, e a Tupi, gradualmente desativada. O empresário Sílvio Santos, por sua vez, ganhando a confiança do governo, obteve a concessão, com o fechamento da TV Tupi, para a TVS, que se transformou depois no SBT, Sistema Brasileiro de Televisão.

A grande imprensa aderiu aos desmandos golpistas, como a Folha de S. Paulo, além das organizações Globo. Segundo Lygia Quartim de Moraes (in Reis, Ridenti e Motta, 2004, p. 300), “o grupo Frias especializou-se na bajulação aos detentores do poder, colocando furgões à disposição da repressão militar. O cronista José Tavares chegou a tomar a elite militar e suas digníssimas famílias como personagens de sua conhecida coluna social".

Em resumo, a repressão teve consequências profundas na cultura nacional da época. O ufanismo generalizado pelo regime causou mudanças no país e os hábitos e modos da população jovem mudaram em relação aos dos períodos anteriores.

A população, impedida de obter informações reais sobre os fatos, parece ter sido iludida em relação ao progresso do país, aderindo ao sistema sem resistência ou questionamento. As telenovelas proliferaram neste período com muito sucesso, tendo sido uma das responsáveis pela alienação geral das massas quanto aos problemas de torturas, desaparecimentos e sequestros em vigência.

REVISTA SIGNOS DO CONSUMO - V.2, N.1, 2010. P. 82-97. 
Em busca de uma compreensão dos signos na propaganda no governo militar de Flailda Brito Garboggini

A programação das TVs também omitia totalmente os acontecimentos, enquanto o cinema brasileiro, nesse período, deu ênfase às porno-chanchadas e a filmes sem conteúdos profundos, o que de certa forma mantinha a população alienada dos fatos reais.

\section{COMERCIAIS SIGNIFICATIVOS - VOLKSWAGEN E US TOP}

Veiculada em TV, a campanha do Volkswagen refletia o aspecto do "Brasil Grande", o ufanismo que o governo mostrava. O "Fusca", nome carinhoso adotado para o carro, aparecia rompendo as barreiras na construção da Transamazônica, um dos maiores signos ufanistas do governo. Esta rodovia, tão bem divulgada na mídia, foi planejada, com mais de quatro mil quilômetros na selva, para atravessar o Brasil do Nordeste ao Norte, terminando no Acre. Visava a garantir uma saída para o Pacífico aos produtos brasileiros e, segundo o Presidente Médici, com ela a Amazônia seria "uma terra sem homens para homens sem terra".

A tentativa de integração nacional (“integrar para não entregar”) por intermédio de uma política cultural era um dos objetivos dos governos militares, principalmente nos governos de Médici (1969- 1974) e Geisel (1974 - 1979). Tal política vislumbrava na televisão uma grande possibilidade de integração via unificação da linguagem, do consumo e da ideologia. Esse interesse dos governos autoritários acabou por confluir com a política de expansão e unificação da programação da Rede Globo no início da década de 70. No final da década, a Globo tornou-se, então, "o produto mais bem acabado do acordo entre militares e burguesia”.

Um comercial veiculado no princípio da década de 70, como parte desta campanha, feita pela Agência de Propaganda Alcântara Machado - que depois se tornou ALMAP (Alcântara Machado e Periscinoto) -, apresentava, em 45 segundos, cenas da construção da Transamazônica, aparecendo o Fusca, apenas nos últimos 15 segundos. A locução informava ser o único veículo capaz de transitar pela estrada ainda em obras, ao lado de tratores e máquinas, mostrando o trabalho de abertura da estrada.

Seria a representação da fase da construção em que ainda os desafios e dificuldades são mostrados, mas o carro segue intrépido, sem medo, e parece conseguir superar todos os obstáculos, inclusive percorrendo distâncias tão grandes. O comercial apresenta as características do automóvel através de comparação da ousadia da obra “monumental" com a intrepidez do Volkswagen. 
Em busca de uma compreensão dos signos na propaganda no governo militar de Flailda Brito Garboggini

Com efeito, a publicidade também se aproveitou de um elemento muito significativo, a liberdade, para fixar a imagem e vender um produto. O comercial de televisão da "US top" tinha 30 segundos, ambientado em uma estação e no trem em que alguns jovens sobem e seguem viagem, cantando e se divertindo de modo muito descontraído. A melodia cantava a mensagem principal do produto: "Liberdade é uma calça velha azul e desbotada". Seguindo com "que você pode usar, do jeito que quiser, não usa quem não quer US top, desbota e perde o vinco... US top, seu jeito de viver. Não usa quem não quer. US top... Denin Indigo Blue".

Toda a ação visual, em conjunto com a música, torna-se fundamental, revelando e estabelecendo características e posicionamento do produto na publicidade.

O comercial no conjunto é dinâmico e descontraído, com pessoas jovens, ágeis e ativas, contrastando com elementos antigos como o trem e um maquinista idoso.

As ações e expressões dos jovens intercalados, no conjunto, passam a sensação de agilidade e liberdade de movimento. Associadas à descontração no modo de sentar, nas roupas estilo "hippie", demonstram a rebeldia da geração.

Eles representavam bem o que Zuenir Ventura (1998, pp. 15-16) coloca: “os nossos heróis são os jovens que cresceram deixando o cabelo e a imaginação crescerem. Eles amavam os Beatles e os Rolling Stones, protestavam ao som de Caetano, Chico ou Vandré, viam Glauber e Godard, andavam com a alma incendiada de paixão revolucionária e não perdoavam os pais por não terem evitado o golpe militar de 64. Era uma juventude que se acreditava política a achava que tudo devia se submeter ao político: o amor, o sexo, a cultura, o comportamento". Porém tudo isso, junto com o sentido real de liberdade, foi tolhido. Geraldo Vandré, com sua música, passou a ser uma das pessoas mais visadas pelos militares e, logo depois do AI5, o compositor mais caçado do país. Sua música "Pra não dizer que não falei das flores", ou simplesmente "Caminhando", tornou-se um hino dos revolucionários, mas levou Vandré à miséria e à apatia.

Os jovens da publicidade podiam demonstrar um certo tipo de ousadia, desde que não desafiassem as forças armadas. $O$ ideal de ser livre fica restrito a: "uma calça velha azul e desbotada que você pode usar do jeito que quiser. Não usa quem não quer. US TOP, seu jeito de viver". As imagens complementam de forma importante essa referência, retratando que afinal o governo não era tão repressor como diziam alguns, permitindo a liberdade no seu modo de ser e viver.

A palavra "liberdade" é utilizada apenas uma vez, mas, até hoje o comercial é REVISTA SIGNOS DO CONSUMO - V.2, N.1, 2010. P. 82-97. 
Em busca de uma compreensão dos signos na propaganda no governo militar de Flailda Brito Garboggini

lembrado como um exemplo dessa liberdade perdida por muitos naquele período.

Todo o contexto refere-se metaforicamente à liberdade de se vestir e de agir e, ao nosso ver, de se expressar. Referências são claras durante toda a letra: "que você pode usar do jeito que quiser" ou "seu jeito de viver". O apelo ao direito de viver e de expressar-se livremente aparece nas entrelinhas.

Não há uma abordagem explícita de contestação ao sistema político, levando em consideração que grande parte da sociedade era favorável às medidas do governo, principalmente nessa época do mencionado "milagre econômico".

\section{CONSIDERAÇÕES FINAIS}

Como pudemos perceber nos estudos, durante o período de 1964 a 1974, o Brasil passou por mudanças, principalmente sócio-culturais.

Essas mudanças foram responsáveis pelo surgimento de movimentos antigovernamentais e atitudes contestadoras. Por outro lado, surgiram fortes movimentos de contenção do direito de liberdade e expressão que interferiram muito na mídia, através da censura e, nesse contexto, constatou-se que a publicidade das empresas amoldou-se ao sistema, tornando-se um instrumento passivo em relação ao autoritarismo. O sistema de governo militar foi repudiado por muitos, de linha socialista, porém, grande parte da sociedade o acolheu, seja por acreditar em seus princípios ou por coerção e medo.

Podemos refletir, hoje, sobre a incapacidade de empresários polemizarem ou contestarem através da publicidade, como alguns músicos e cineastas tentaram fazer. Questiono se muitos realmente haviam aderido ao sistema ou se as pressões políticas é que os levavam a agir de tal forma. Os anunciantes não enfrentaram as pressões, não levantaram bandeiras contrárias ao governo. Muitos, posteriormente, declararam-se tolhidos, sem poder ir contra a corrente pela sobrevivência.

Efetivamente, com o autoritarismo e diante de seus próprios interesses econômicos, muitos preferiram aderir e as agências de publicidade e anunciantes, ainda que discordassem, viam-se limitados fortemente. Dessa forma, os meios de comunicação permitiam e, muitas vezes, até contribuíram para que o regime exercesse poder absoluto sobre a informação. O comodismo imperou, a adesão foi muito mais conveniente e produtiva do que a oposição e a resistência.

A propaganda deu resultados e, assim como grande parte da população, acreditou 
Em busca de uma compreensão dos signos na propaganda no governo militar de Flailda Brito Garboggini

que os governos militares eram legítimos e defendiam seus interesses. Muitos consideraram que os objetivos foram alcançados e que o país superou a crise em que se encontrava em 1964, expandindo-se o sistema financeiro. O capital estrangeiro foi investido em todos os setores, diversificando a agricultura e desenvolvendo a indústria. Porém, como sempre, os grandes beneficiários foram os proprietários do grande capital, que viram sua riqueza multiplicar-se rapidamente. Tais fatos nos revelam que o apoio ao regime ditatorial era compensador para muitas organizações.

A ditadura soube recompensar os que a enalteceram ou cumpriram o código de boa conduta por ela idealizada. A mídia, em geral, tornou-se importante na sustentação e difusão desse que foi um dos regimes mais duros e limitantes que já vivemos.

Os comerciais analisados demonstraram como contribuíram para enaltecer as grandes obras. A campanha da Volkswagen fazia apologia ao governo e à grandiosidade da Transamazônica com a intrepidez do Fusca. O comercial do jeans US-top dava ênfase à liberdade num tempo em que ela era apenas um sonho ou "uma calça velha, azul e desbotada".

\section{REFERÊNCIAS BIBLIOGRÁFICAS}

AZEVEDO, Carlos. O pesadelo recorrente. In O golpe de 64. Jornal Caros amigos Especial, março 2004, p. 4.

DINES, Alberto. A República - de 1964 a 2004, copyright Jornal do Brasil, 27/03/04. Observatório da Imprensa, Ano 12, n 270, 30/03/2004.

GARBOGGINI, F.B. Semiótica, uma ciência para comunicar. Revista de Letras, Vol. 23, PUC-Campinas, Dezembro de 2004, p.67-81.

. A semiótica como instrumento de análise da publicidade. Comunicarte, CLC, PUCCampinas, 2003, p. 37-52.

MARCONDES, Pyr. Uma história da propaganda brasileira. Rio de Janeiro: Ediouro, 2001.

PINHO, J.B.(org.) Trajetórias e questões contemporâneas da publicidade brasileira. São Paulo: Intercom, coleção GT’s, n. 3, 1995.

REIS, D., RIDENTI, M., MOTTA, R. O golpe e a ditadura militar. 40 anos depois (1964-2004). Bauru: Edusc, 2004.

VENTURA, Zuenir 1968 - o ano que não terminou. Rio de Janeiro: Nova Fronteira, 
Em busca de uma compreensão dos signos na propaganda no governo militar de Flailda Brito Garboggini

1988.

Artigo recebido em 19/12/2009.

Aprovado em 9/3/2010. 